\title{
Health Reform and Changes in Health Insurance Coverage in 2014
}

\section{Citation}

Sommers, Benjamin D., Thomas Musco, Kenneth Finegold, Munira Z. Gunja, Amy Burke, and Audrey M. McDowell. 2014. "Health Reform and Changes in Health Insurance Coverage in 2014." N Engl J Med 371 (9) (August 28): 867-874. doi:10.1056/nejmsr1406753.

\section{Published Version}

doi:10.1056/NEJMsr1406753

\section{Permanent link}

http://nrs.harvard.edu/urn-3:HUL.InstRepos:14008382

\section{Terms of Use}

This article was downloaded from Harvard University's DASH repository, and is made available under the terms and conditions applicable to Other Posted Material, as set forth at http:// nrs.harvard.edu/urn-3:HUL.InstRepos:dash.current.terms-of-use\#LAA

\section{Share Your Story}

The Harvard community has made this article openly available.

Please share how this access benefits you. Submit a story.

\section{Accessibility}


S P E C I A R E PORT

\title{
Health Reform and Changes in Health Insurance Coverage in 2014
}

\author{
Benjamin D. Sommers, M.D., Ph.D., Thomas Musco, B.B.A., Kenneth Finegold, Ph.D., \\ Munira Z. Gunja, M.P.H., Amy Burke, Ph.D., and Audrey M. McDowell, M.S.
}

Open enrollment under the Affordable Care Act (ACA), the most ambitious attempt to expand health coverage in the United States in decades, began October 1, 2013. The law offers Medicaid eligibility to citizens and qualified legal immigrants with incomes at or below $138 \%$ of the federal poverty level in participating states and tax credits for private insurance purchased via marketplaces for persons not eligible for Medicaid who have incomes between $100 \%$ and $400 \%$ of the federal poverty level. ${ }^{1}$ The effect of these provisions on insurance coverage and access to care is of critical policy interest.

Preliminary reports from rapid-turnaround surveys have described a decline in the uninsured rate since the fall of 2013, when open enrollment began..$^{2-5}$ However, numerous factors, including the economy, survey sampling error, and preexisting trends, can affect estimated rates of Americans without insurance. More generally, the systemic changes brought by the ACA pose a particular challenge for identifying the effect of the law, owing to the lack of a control group. Although to date 24 states have not expanded Medicaid, the ACA has major implications for these states, owing to subsidized marketplace coverage, the individual mandate, and a streamlined application process for uninsured persons who were previously eligible for Medicaid. ${ }^{6}$ An additional question is how quickly any coverage changes will lead to improved access to care.

Our study had two main objectives. We wanted to determine, first, whether the pattern of recent coverage changes is consistent with early effects of the ACA and, second, whether any changes in access to care are yet evident.

$$
\text { METHODS }
$$

\section{ANALYTIC APPROACH}

We used three approaches to test for associations between the ACA open-enrollment period and coverage changes, using the largest national daily poll on health issues, the Gallup-Healthways Well-Being Index (WBI). First, we assessed coverage changes in the fourth quarter of 2013 and the first two quarters of 2014, using multivariate regression to adjust for the preexisting trend and potential confounders such as employment, income, and demographic characteristics.

Second, we tested for differential effects in the subgroups most likely to gain insurance under the ACA. As noted above, the ACA affects all states; however, coverage gains should vary according to income and state decisions regarding Medicaid expansion. Newly available subsidized coverage under the ACA is targeted to lowincome adults $(\leq 138 \%$ of the federal poverty level) in states expanding Medicaid and middleincome adults (139 to $400 \%$ of the poverty level) in all states. Adults with income that is greater than $400 \%$ of the poverty level may experience changes due to the mandate, cancellations of previous plans, ${ }^{7}$ and other regulations, but these effects are likely to be smaller than for other groups.

Third, we tested for an association between survey-reported coverage changes and state-level marketplace and Medicaid enrollment statistics from the Department of Health and Human Services (HHS). Although HHS enrollment reports capture data both on persons who were 
uninsured previously and on those who had coverage beforehand, if insurance changes are due to the ACA, these state statistics should be correlated with survey-reported coverage gains. Last, we tested for any changes in access to care using a similar multivariate approach.

\section{DATA SOURCES}

The most widely cited estimates of the uninsured population come from surveys conducted by the U.S. Census Bureau and the National Center for Health Statistics, which feature nationally representative sampling and high response rates, with the use of mailed and in-person interviews. However, they feature a time lag ranging from 6 to 18 months. Thus, early estimates of the effects of ACA coverage must rely on other sources.

Our primary data set was the Gallup-Healthways WBI, purchased from Gallup, for January 1 , 2012, through June 30, 2014. The WBI is a daily telephone survey that asks a national sample of adults questions about health insurance, access to care, and health status. Like other data sets analyzed to describe coverage changes in 2014, the WBI is a rapid-turnaround survey with a much lower response rate $(11 \%$, on the basis of Response Rate 3, as defined by the American Association for Public Opinion Research) than government-conducted surveys. ${ }^{8}$ Previous research validated WBI estimates of the uninsured rate, as compared with well-established government-conducted surveys, with year-to-year correlations (2008-2011) with the American Community Survey and Current Population Survey of 0.87 and 0.85 , respectively, and state-level correlations of 0.95 and 0.89 , respectively. ${ }^{8}$ Although the WBI has undergone some changes since 2011 — including a reduction in sample size - questions for the outcomes studied here (see the Supplementary Appendix, available with the full text of this article at NEJM.org) have not changed. Even after the sample-size reduction, the WBI still has by far the largest sample among these rapid-turnaround data sources (with approximately 30,000 nonelderly [ $<65$ years of age] adults surveyed in each quarter, as compared with 2500 to 7500 adults in other surveys ${ }^{2,5,9}$ ).

We compared WBI survey data with HHS enrollment statistics for Medicaid and marketplace coverage in each state during the open-enroll- ment period. These statistics are based on administrative data collected by the federally facilitated marketplace and data submitted to the Centers for Medicare and Medicaid Services by state-based marketplaces (see the Supplementary Appendix). We also used information on state decisions regarding Medicaid expansion as of January $2014 .^{10}$

\section{STATISTICAL ANALYSIS}

The sample included adults 18 to 64 years of age. Our study period was January 1, 2012, through June 30, 2014. Our primary model did not include data from before 2012, because coverage was changing rapidly during this period for several million adults owing to the provision in the ACA enabling young adults to stay on their parents' insurance plans until 26 years of age. This means that our results do not capture effects of that provision, which has been well studied in previous research. ${ }^{11-16}$ Similarly, our analysis does not estimate coverage gains from early Medicaid expansions that began in 2010 and 2011, which were generally much more limited than the 2014 changes. ${ }^{17}$ Our sample excluded adults 65 years of age or older, who are overwhelmingly enrolled in Medicare and thus ineligible for the coverage expansion under the ACA. The sample included 420,449 adults.

The primary outcome was insurance status at the time of the survey (insured vs. uninsured), and the secondary outcomes were two measures of access to care - having a personal doctor and having difficulty paying for medical care in the past year. The WBI has been validated for these measures, but it less reliably distinguishes between different types of coverage (e.g., Medicaid vs. private insurance). ${ }^{8}$ We used multivariate regression to model the likelihood of each outcome over time. The primary analysis modeled a linear monthly time trend, with sensitivity analyses that either added a quadratic time trend or did not include a time trend. We created binary variables for the beginning of the open-enrollment period (fourth quarter of 2013), for the beginning of the new coverage options (first quarter of 2014), and for the first full quarter after open enrollment (second quarter of 2014).

These variables measured any change in outcome at that point in time as compared with the baseline trend (before October 2013). Some pre- 
vious analyses have focused on changes in coverage comparing the fourth quarter of 2013 with the first quarter of 2014, ${ }^{3}$ which may underestimate the effect of the ACA, since some people applying in the fall of 2013 were probably already eligible for Medicaid and were enrolled as a result of greater awareness regarding coverage options under the ACA.

All models (see the Supplementary Appendix) were adjusted for demographic and economic covariates: age, race, ethnic group, sex, household income, employment status, and state of residence. We also analyzed results for subgroups based on age, sex, and race or ethnic group.

We conducted a stratified analysis that was based on household income level and state decisions regarding Medicaid expansion. Gallup asks respondents to report household income in categories ranging from $\$ 0$ to $\$ 10,000$ per month and does not impute missing values. To convert income information and household size into a percentage of the federal poverty level, we used the midpoint of each income range and imputed missing values using a multivariate regression model, as in prior research (see the Supplementary Appendix). ${ }^{8}$ We then analyzed distinct income groups in states that were expanding Medicaid versus in states that were not: up to $138 \%$ of the federal poverty level (eligible for Medicaid in states with Medicaid expansion), 139 to $400 \%$ of the poverty level (eligible for tax credits in all states), and more than $400 \%$ of the poverty level (not eligible for subsidized coverage). We also compared the effect of state decisions regarding Medicaid expansion using a differences-in-differences analysis for low-income adults in states with Medicaid expansion versus those in states without Medicaid expansion.

We then compared survey-based coverage changes with enrollment reports from the HHS, ${ }^{18}$ dividing the total enrollment in each state by the size of its nonelderly population. This HHS enrollment variable captured the approximate percentage of the state population that signed up for ACA-related coverage through the marketplaces by the end of March 2014. We used the same regression approach as above, with the addition of an interaction term between the second quarter of 2014 and the HHS enrollment variable. This measured the relationship between the changes in the uninsured rate in the second quarter of 2014 and the per capita HHS enrollment statistics in each state. This analysis used robust standard errors clustered at the state level.

For ease of interpretation, we expressed our results as adjusted changes in the probability of each outcome, on the basis of linear probability models. Logistic-regression models - with results converted to predicted probabilities produced nearly identical results.

This project was exempt from review by an institutional review board under federal regulations since it used deidentified secondary data. Analyses were conducted with the use of Stata software, version 12.0 (StataCorp), to account for the stratified survey design. Estimates were calculated with the use of nationally representative survey weights from Gallup, which were based on national targets according to age, sex, race or ethnic group, educational level, geographic region, and telephone status (see the Supplementary Appendix).

\section{RESULTS}

\section{DESCRIPTIVE STATISTICS}

Table 1 presents descriptive statistics for the sample. The average age of the respondents was 41.1 years. A total of $63 \%$ of the sample was white, 15\% Hispanic, and 10\% black.

\section{UNADJUSTED TRENDS IN INSURANCE COVERAGE}

Figure 1 shows the unadjusted trends in the percentage of adults 18 to 64 years of age who did not have health insurance. The uninsured rate was just above $20 \%$ for most of 2012, before a slight rise in the early part of 2013. The uninsured rate was $21.0 \%$ in September 2013, right before the beginning of the open-enrollment period, and it fell to $16.3 \%$ in April 2014. The uninsured rate was stable from April through June 2014, after the end of open enrollment.

\section{ADJUSTED CHANGES IN COVERAGE ASSOCIATED WITH OPEN ENROLLMENT}

Table 2 presents adjusted estimates of the change in coverage associated with open enrollment. As compared with the baseline trend, the percentage of adults without insurance had declined by 5.2 percentage points $(\mathrm{P}<0.001)$ by the second quarter of 2014. Adding a quadratic time trend, 


\begin{tabular}{|lcc|}
\hline Table 1. Characteristics of the Study Sample.* & \\
\hline Variable & $\begin{array}{c}\text { Respondents } \\
(\mathbf{N}=\mathbf{4 2 0 , 4 4 9 )}\end{array}$ & $\begin{array}{c}\text { Unweighted } \\
\text { No. of } \\
\text { Respondents }\end{array}$ \\
Mean age (yr) & 41.1 & NA \\
Male sex (\%) & 50 & 220,137 \\
Race or ethnic group (\%) $广$ & & \\
White non-Hispanic & 63 & 288,629 \\
Hispanic & 15 & 44,640 \\
Black non-Hispanic & 10 & 33,708 \\
Asian non-Hispanic & 2 & 8,390 \\
Other & 8 & 33,028 \\
Do not know or declined to answer & 2 & 12,054 \\
Household income (\%) & & \\
$\quad \leq 138 \%$ of FPL & 14 & 36,102 \\
139-400\% of FPL & 58 & 217,338 \\
$>400 \%$ of FPL & 28 & 167,009 \\
Currently employed (\%) & 71 & 306,153
\end{tabular}

* The results in the table show the authors' analysis of survey data from the Gallup-Healthways Well-Being Index, 2012-2014. All estimates were calculated with the use of nationally representative survey weights; the unweighted numbers are also provided. Percentages may not total $100 \%$ because of rounding. FPL denotes federal poverty level, and NA not applicable.

$\uparrow$ Race and ethnic group were self-reported.
Medicaid expansion ( -9.0 percentage points and -5.5 percentage points, respectively; $\mathrm{P}<0.001$ for both comparisons). In an analysis directly comparing low-income adults in states with Medicaid expansion versus those in states without, Medicaid expansion was associated with a reduction of 5.1 percentage points $(\mathrm{P}=0.01)$ in the uninsured rate in 2014, as compared with states without Medicaid expansion (Table S1 in the Supplementary Appendix). Results from Table 3 were similar when we excluded persons with missing income information from the analysis instead of imputing those values (Table S2 in the Supplementary Appendix).

\section{ASSOCIATION WITH HHS ENROLLMENT STATISTICS}

Survey-reported coverage changes were significantly associated with state-level per capita HHS enrollment statistics (Table S3 in the Supplementary Appendix). The coefficient of -0.53 $(\mathrm{P}<0.001)$ indicated that each percentage-point increase in HHS enrollment was associated with a decline of 0.53 percentage points in the uninsured rate in the state. The coefficient for the second quarter of 2014 in this model was still significant $(-2.4, \mathrm{P}<0.002)$, indicating that a portion of the decline in the uninsured rate in that quarter was not directly associated with HHS state-level enrollment statistics.

omitting the time trend, or considering alternative timeframes (2013-2014 and 2010-2014) produced estimates of declines ranging from 4.2 to 7.1 percentage points $(\mathrm{P}<0.001$ for all comparisons) (Table S1 in the Supplementary Appendix). Declines in the uninsured rate were significant $(\mathrm{P}<0.001)$ for all subgroups on the basis of age, sex, and race or ethnic group, with the largest changes occurring among Hispanics, blacks, and adults 18 to 34 years of age.

Table 3 shows changes in coverage on the basis of household income level and state Medicaid-expansion plans. By the second quarter of 2014, there had been a decline of 6.0 percentage points $(\mathrm{P}=0.006)$ in the uninsured rate for persons with incomes at or below $138 \%$ of the federal poverty level in states with Medicaid expansion and a nonsignificant decline of 3.1 percentage points $(\mathrm{P}=0.13)$ in states without Medicaid expansion. As compared with the baseline trend, the uninsured rate declined for persons with incomes of 139 to $400 \%$ of the federal poverty level both in states with and in those without

\section{MEASURES OF ACCESS TO CARE}

We also detected significant changes in access to care in 2014, as compared with baseline trends. By the second quarter of 2014, there had been an increase of 2.2 percentage points in the likelihood of having a personal doctor $(\mathrm{P}<0.001)$ and a decrease of 2.7 percentage points in the proportion of adults unable to afford medical care $(\mathrm{P}<0.001)$.

\section{DISCUSSION}

In this analysis of nationally representative survey data from January 2012 through June 2014, we found a significant decline in the uninsured rate among nonelderly adults that coincided with the initial open-enrollment period under the ACA. These changes remained highly significant after adjustment for potential confounders such as employment, demographic characteristics, and income. As compared with the baseline 


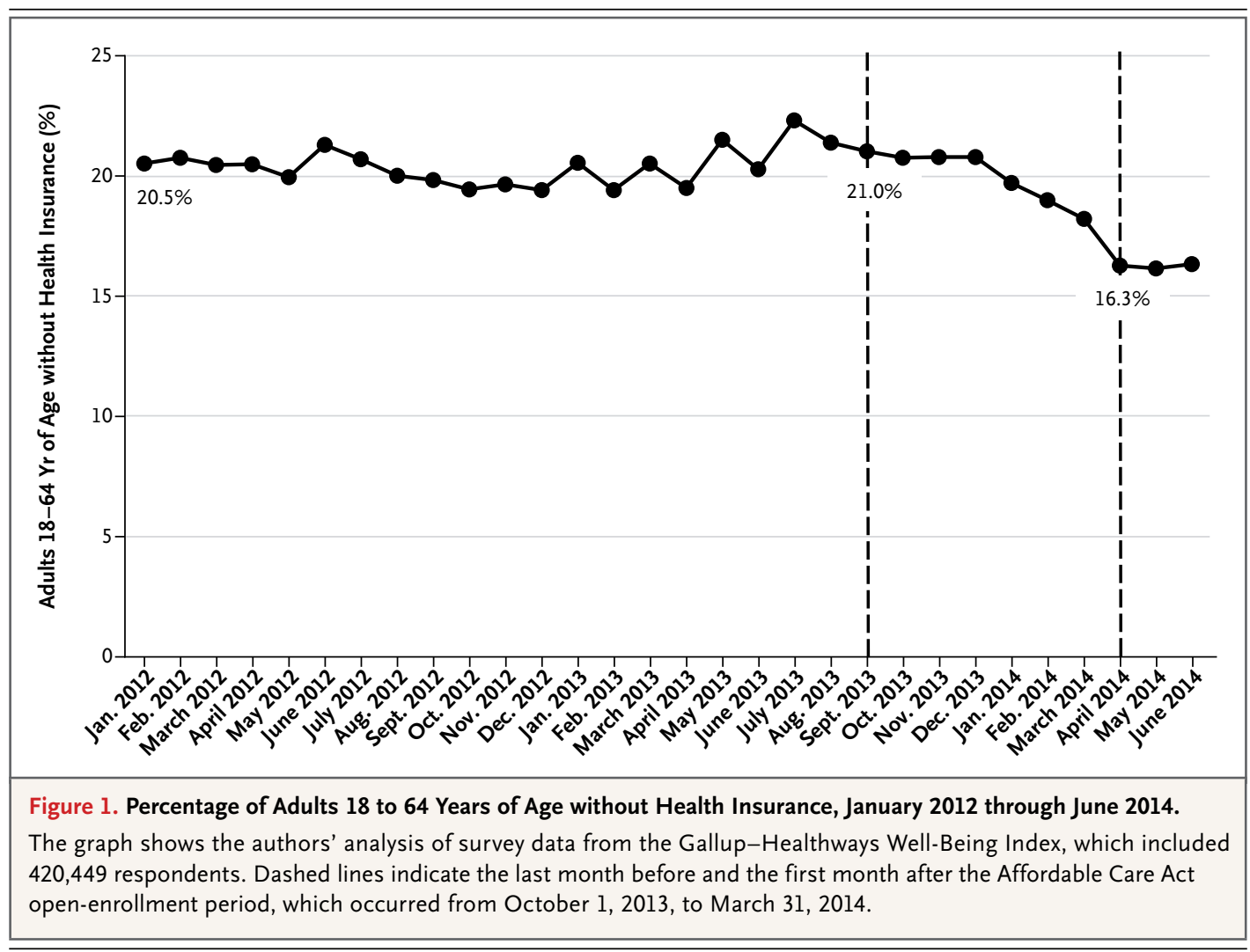

trend, the uninsured rate declined by 5.2 percentage points by the second quarter of 2014, a $26 \%$ relative decline from the 2012-2013 period. Combined with 2014 Census estimates of 198 million adults 18 to 64 years of age, ${ }^{19}$ this corresponds to 10.3 million adults gaining coverage, although depending on the model and confidence intervals, our sensitivity analyses imply a wide range from 7.3 to 17.2 million adults.

The pattern of coverage gains was consistent with the effects of the ACA, with major gains for persons likely to be eligible for expanded Medicaid on the basis of their income and state of residence but smaller and nonsignificant changes for low-income adults in states without Medicaid expansion. Coverage gains were significant both in states with Medicaid expansion and in those without Medicaid expansion for persons with incomes between 139\% and 400\% of the federal poverty level, which is consistent with tax subsidies under the ACA for private insurance in this income range, regardless of state decisions regarding Medicaid expansion. Absolute gains were largest among young adults and
Hispanics, two groups with high uninsured rates at baseline. State-level estimates of coverage gains were significantly associated with official HHS enrollment statistics, showing that each percentage point of the state population enrolling via the marketplaces was associated with a half-point decline in the uninsured rate. Nonetheless, the inherent lack of a control group precludes a causal interpretation for these findings, and other unmeasured factors may have contributed to these changes.

Overall, our results are consistent with the broad patterns identified previously in the GallupHealthways WBI and several other nongovernmental surveys, ${ }^{2,4,5,20,21}$ as well as a recent review of national ACA enrollment figures. ${ }^{22}$ Our study adds to these previous findings by adjusting both for potential confounders and for preexisting trends, as well as showing that these changes were associated with ACA enrollment statistics in each state.

We found evidence that within the first 6 months of gaining insurance, more adults reported having a personal doctor and fewer had 


\begin{tabular}{|c|c|c|c|c|c|}
\hline \multirow[t]{3}{*}{ Population } & $\begin{array}{c}\text { Baseline } \\
\text { Uninsured } \\
\text { Rate' }\end{array}$ & \multicolumn{2}{|c|}{ First Quarter, 2014} & \multicolumn{2}{|c|}{ Second Quarter, 2014} \\
\hline & & $\begin{array}{l}\text { Change from } \\
\text { Baseline Trend } \\
(95 \% \mathrm{Cl})\end{array}$ & P Value & $\begin{array}{l}\text { Change from } \\
\text { Baseline Trend } \\
(95 \% \mathrm{Cl})\end{array}$ & P Value \\
\hline & percent & percentage points & & percentage points & \\
\hline All respondents & 20.3 & $-2.6(-3.4$ to -1.9$)$ & $<0.001$ & $-5.2(-6.0$ to -4.5$)$ & $<0.001$ \\
\hline \multicolumn{6}{|l|}{ Sex } \\
\hline Male & 21.8 & $-2.4(-3.5$ to -1.3$)$ & $<0.001$ & $-5.0(-6.1$ to -3.9$)$ & $<0.001$ \\
\hline Female & 18.9 & $-2.8(-3.9$ to -1.8$)$ & $<0.001$ & $-5.5(-6.6$ to -4.4$)$ & $<0.001$ \\
\hline \multicolumn{6}{|l|}{ Race or ethnic group } \\
\hline White non-Hispanic & 14.3 & $-1.8(-2.6$ to -1.0$)$ & $<0.001$ & $-4.0(-4.8$ to -3.2$)$ & $<0.001$ \\
\hline Black non-Hispanic & 22.4 & $-4.3(-6.8$ to -1.9$)$ & 0.001 & $-6.8(-9.3$ to -4.2$)$ & $<0.001$ \\
\hline Hispanic & 41.8 & $-3.9(-6.4$ to -1.4$)$ & 0.002 & $-7.7(-10.4$ to -5.1$)$ & $<0.001$ \\
\hline \multicolumn{6}{|l|}{ Age } \\
\hline $18-34 \mathrm{yr}$ & 26.0 & $-3.8(-5.3$ to -2.4$)$ & $<0.001$ & $-6.5(-8.0$ to -5.0$)$ & $<0.001$ \\
\hline $35-44 \mathrm{yr}$ & 21.1 & $-2.0(-3.7$ to -0.2$)$ & 0.03 & $-4.6(-6.4$ to -2.8$)$ & $<0.001$ \\
\hline $45-64 \mathrm{yr}$ & 15.5 & $-2.0(-2.9$ to -1.0$)$ & $<0.001$ & $-4.5(-5.4$ to -3.5$)$ & $<0.001$ \\
\hline
\end{tabular}

* All models used nationally representative survey weights and were adjusted for age, sex, race, ethnic group, employment status, household income, state of residence, and a linear time trend. Analyses also included a binary variable for the fourth quarter of 2013 (data not shown). Cl denotes confidence interval.

$\uparrow$ The baseline uninsured rate was the mean uninsured rate for the population from the first quarter of 2012 through the third quarter of 2013.

difficulties paying for medical care - even though the latter measure asked about the prior 12 months. These results are consistent with studies of previous insurance expansions that have shown that gains in coverage can lead to rapid improvements in access. ${ }^{13,23-26}$

Our study has important limitations. As discussed earlier, the response rate for rapid-turnaround data sources such as the WBI is much lower than that for government-conducted surveys. ${ }^{8,9}$ However, Gallup polls and similar data sets are used regularly to offer timely evaluations of population-level phenomena, including health care-related issues ${ }^{27,28}$ and elections. ${ }^{29-31}$ More importantly, the WBI has been validated against government-conducted surveys for this type of analysis of the uninsured rate, although the same study concluded that the WBI does not reliably measure the type of insurance a person has. ${ }^{8}$ In addition, the WBI does not provide information on children's insurance coverage, which may also change under the ACA. ${ }^{32,33}$
The income information in the WBI is limited, which means that our estimates of income as a percentage of poverty are imprecise, and previous research has shown that the survey overrepresents the middle of the income distribution. ${ }^{8}$ Nonetheless, we found logical patterns of coverage on the basis of these measurements, and results were similar when we excluded observations with missing income data.

The HHS enrollment reports also have limitations. For applications sent directly to state Medicaid agencies, the HHS was unable to consistently distinguish between persons enrolling for the first time and those renewing coverage. For that reason, we used only enrollment statistics that were based on marketplace determinations of eligibility for Medicaid and private coverage, rather than those made directly by state Medicaid agencies. The reports also do not measure off-marketplace nongroup (private) coverage or employer-sponsored coverage, both of which may undergo ACA-related changes. ${ }^{22,34}$ 


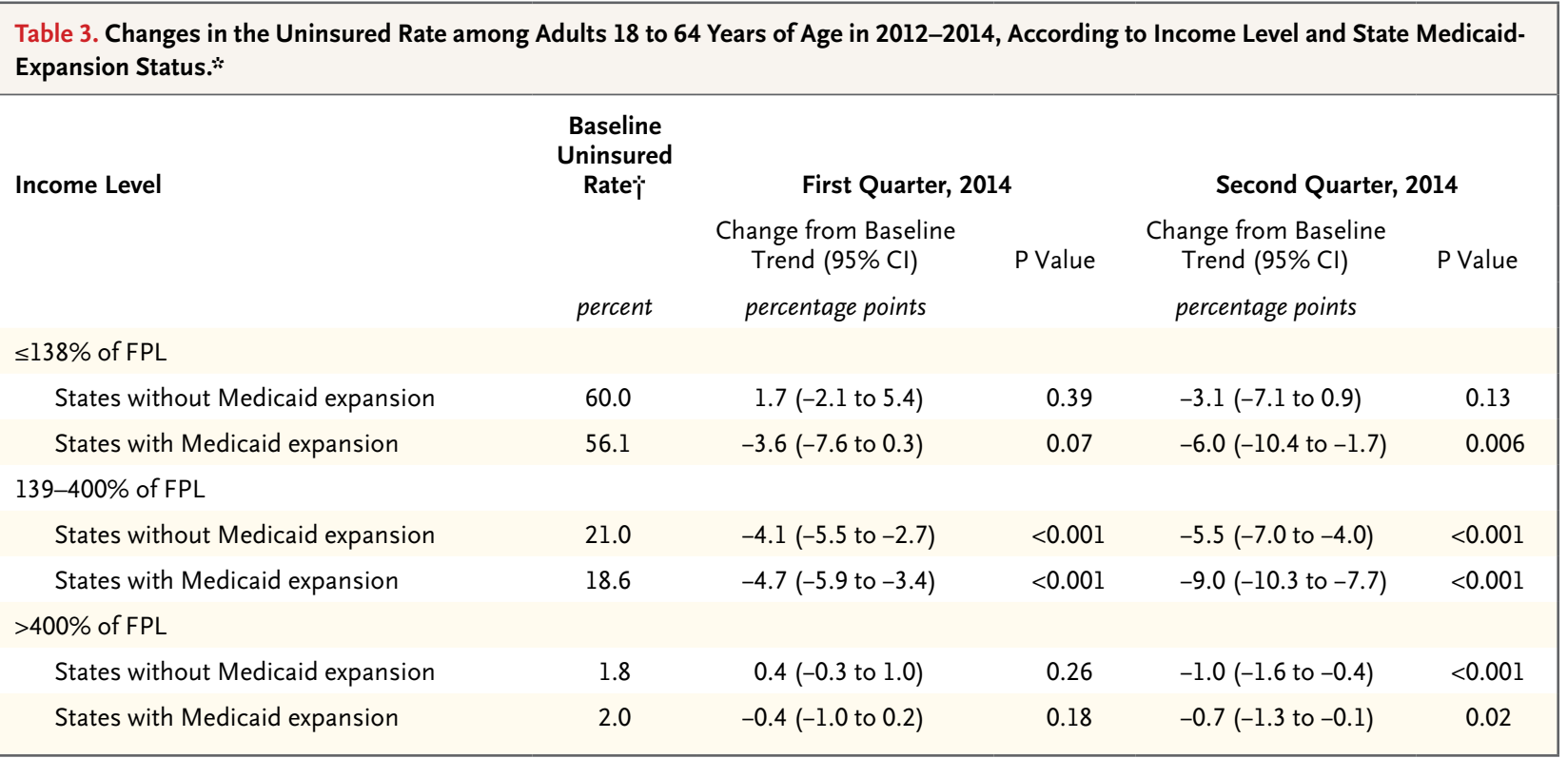

* All models used nationally representative survey weights and were adjusted for age, sex, race, ethnic group, employment status, household income, state of residence, and a linear time trend. Analyses also included a binary variable for the fourth quarter of 2013 (data not shown).

$\dagger$ The baseline uninsured rate was the mean uninsured rate for the population from the first quarter of 2012 through the third quarter of 2013.

This means that the HHS statistics do not fully capture all new ACA-related enrollment, but we nonetheless detected a strong association between these figures and the uninsured rates in the survey.

Finally, although our multifaceted approach offers substantial improvements over previous reports, these analyses are merely observational. We can only identify suggestive associations between the ACA, the declining uninsured rate, and access to care.

In conclusion, we found that the number of Americans without health insurance declined significantly since the ACA open-enrollment period began in October 2013. The patterns of coverage changes were consistent with the eligibility criteria in the law regarding subsidized coverage and HHS statistics on state-level enrollment in ACA programs. National estimates of coverage after the open-enrollment period will not be available from federal surveys until late 2014, and reliable state-level estimates will not be available until the fall of 2015. Future research with these government-conducted surveys will be valuable to corroborate these find- ings, monitor future trends, and further assess the downstream effects of coverage.

The views expressed in this article are those of the authors and do not represent the official views of the Department of Health and Human Services.

Disclosure forms provided by the authors are available with the full text of this article at NEJM.org.

From the Office of the Assistant Secretary for Planning and Evaluation, Department of Health and Human Services, Washington, DC (B.D.S., T.M., K.F., M.Z.G., A.B., A.M.M.); and the Department of Health Policy and Management, Harvard School of Public Health and Brigham and Women's Hospital, Boston (B.D.S.).

This article was published on July 23, 2014, at NEJM.org.

1. Summary of the Affordable Care Act. Washington, DC: Kaiser Family Foundation, 2013.

2. Carman KG, Eibner C. Changes in health insurance enrollment since 2013: evidence from the RAND Health Reform Opinion Study. Santa Monica, CA: RAND, 2014.

3. Levy J. U.S. uninsured rate drops to $13.4 \%$. Gallup WellBeing. May 5, 2014 (http://www.gallup.com/poll/168821/uninsured -rate-drops.aspx).

4. Long SK, Kenney GM, Zuckerman S, et al. QuickTake: number of uninsured adults falls by 5.4 million since 2013. Washington, DC: Urban Institute, 2014.

5. Collins SR, Rasmussen PW, Doty MM. Gaining ground: Americans' health insurance coverage and access to care after the Affordable Care Act's first open enrollment period. New York: Commonwealth Fund, 2014. 
6. Sommers BD, Epstein AM. Why states are so miffed about Medicaid - economics, politics, and the "woodwork effect." N Engl J Med 2011;365:100-2.

7. Sommers BD. Insurance cancellations in context: stability of coverage in the nongroup market prior to health reform. Health Aff (Millwood) 2014;33:887-94.

8. Skopec L, Musco T, Sommers BD. A potential new data source for assessing the impacts of health reform: evaluating the Gallup-Healthways Well-Being Index. Healthcare J Delivery Sci Innov 2014;2:113-20.

9. Long SK, Kenney GM, Zuckerman S, et al. The health reform monitoring survey: addressing data gaps to provide timely insights into the affordable care act. Health Aff (Millwood) 2014; 33:161-7.

10. State Medicaid and CHIP income eligibility standards, effective January 1, 2014. Baltimore: Centers for Medicare \& Medicaid Services (http://www.medicaid.gov/AffordableCareAct/Medicaid -Moving-Forward-2014/Downloads/Medicaid-and-CHIP-Eligibility -Levels-Table.pdf).

11. Mulcahy A, Harris K, Finegold K, Kellermann A, Edelman L, Sommers BD. Insurance coverage of emergency care for young adults under health reform. N Engl J Med 2013;368:2105-12.

12. Chua KP, Sommers BD. Changes in health and medical spending among young adults under health reform. JAMA 2014; 311:2437-9.

13. Sommers BD, Buchmueller T, Decker SL, Carey C, Kronick R. The Affordable Care Act has led to significant gains in health insurance and access to care for young adults. Health Aff (Millwood) 2013;32:165-74.

14. Sommers BD, Kronick R. The Affordable Care Act and insurance coverage for young adults. JAMA 2012;307:913-4

15. Antwi YA, Moriya AS, Simon K. Effects of federal policy to insure young adults: evidence from the 2010 Affordable Care Act's dependent coverage mandate. Cambridge, MA: National Bureau of Economic Research, 2012.

16. Cantor JC, Monheit AC, DeLia D, Lloyd K. Early impact of the Affordable Care Act on health insurance coverage of young adults. Health Serv Res 2012;47:1773-90.

17. Sommers BD, Kenney GM, Epstein AM. New evidence on the Affordable Care Act: coverage impacts of early Medicaid expansions. Health Aff (Millwood) 2014;33:78-87.

18. Health Insurance Marketplace: summary enrollment report for the initial annual open enrollment period. Washington, DC: Department of Health and Human Services, Office of the Assistant Secretary for Planning and Evaluation, 2014 (http://aspe.hhs .gov/health/reports/2014/MarketPlaceEnrollment/Apr2014/ib_ 2014Apr_enrollment.pdf).

19. 2012 National population predictions: downloadable files. Washington, DC: Census Bureau, 2014 (https://www.census.gov/ population/projections/data/national/2012/downloadablefiles .html).

20. Levy J. In U.S., uninsured rate lowest since 2008. Gallup
Well-Being. April 7, 2014 (http://www.gallup.com/poll/168248/ uninsured-rate-lowest-2008.aspx).

21. Clemans-Cope L, Karpman M, Weiss A, Anderson N. Increase in Medicaid under the ACA reduces uninsurance, according to early estimates. Washington, DC: Urban Institute, 2014. 22. Blumenthal D, Collins SR. Health care coverage under the Affordable Care Act — a progress report. N Engl J Med 2014;371: 275-81.

23. Sommers BD, Long SK, Baicker K. Changes in mortality after Massachusetts health care reform: a quasi-experimental study. Ann Intern Med 2014;160:585-93.

24. Baicker K, Taubman SL, Allen HL, et al. The Oregon experiment - effects of Medicaid on clinical outcomes. N Engl J Med 2013;368:1713-22

25. Finkelstein A, Taubman S, Wright BJ, et al. The Oregon health insurance experiment: evidence from the first year. Q J Econ 2012;127:1057-106.

26. Long SK, Coughlin T, King J. How well does Medicaid work in improving access to care? Health Serv Res 2005;40:39-58.

27. Mendes E. In U.S., significantly fewer 18- to 25-year-olds uninsured. Gallup Well-Being. September 21, 2011 (http://www .gallup.com/poll/149558/Significantly-Fewer-Year-Olds-Uninsured .aspx).

28. Blendon RJ, Benson JM. The public and the conflict over future Medicare spending. N Engl J Med 2013;369:1066-73.

29. Holbrook AL, Krosnick JA, Pfent A. The causes and consequences of response rates in surveys by the news media and government contractor survey research employers. In: Lepowski JM, Tucker C, Brick JM, et al., eds. Advances in telephone survey methodology. Hoboken, NJ: John Wiley \& Sons, 2008:499-28.

30. Assessing the representativeness of public opinion surveys. Pew Research Center. May 15, 2012 (http://www.people-press.org/ files/legacy-pdf/Assessing\%20the\%20Representativeness \%20of $\% 20$ Public\%200pinion\%20Surveys.pdf).

31. Blendon RJ, Benson JM, Brulé A. Implications of the 2012 election for health care - the voters' perspective. $N$ Engl J Med 2012;367:2443-7.

32. Kenney GM, Buettgens $M$, Guyer J, Heberlein M. Improving coverage for children under health reform will require maintaining current eligibility standards for Medicaid and CHIP. Health Aff (Millwood) 2011;30:2371-81.

33. Pilkey D, Skopec L, Gee E, Finegold K, Amaya K, Robinson W. The Affordable Care Act and adolescents. Washington, DC: Department of Health and Human Services, Office of the Assistant Secretary for Planning and Evaluation, 2013.

34. Hamel L, Levitt L, Claxton G, Cox C, Pollitz K, Brodie M. Survey of non-group health insurance enrollees: a first look at people buying their own health insurance following implementation of the Affordable Care Act. Washington, DC: Kaiser Family Foundation, 2014.

DOI: 10.1056/NEJMsr1406753

Copyright $\odot 2014$ Massachusetts Medical Society. 